the European horizon. The discussion of these observations in conjunction with those made in the northern hemisphere, will lead to a much more precise knowledge of the orbit than we have at present.

OLBERS' COMET OF 1815 . - In a recent note upon this comet it should have been stated that, acting upon the wish expressed by Olbers at the time, Triesnecker printed his observed differences of right ascension and declination between the comet and comparison-stars in Zeitschrift fiir Astronomie, vol. ii. The Vienna observations, therefore, admit of a new reduction, in addition to those previously named.

\section{DIURNAL OSCILLATIONS OF THE BAROMETER}

$I^{N}$ the "Meteorological Notes" which appeared in 1 NATURE, vol. xviii. p. 198, , some interesting results are referred to, which show marked differences in the diurnal variations of the barometer at places quite near to each other, as Greenwich, Kew, Oxford. It is remarked especially that the forenoon maximum in the months of May to July occurs near 9 A.M. at Greenwich, and near 8 A.M. at Kew; while at Falmouth and Valentia it is delayed to II A.M., or noon, and occurs in June as late as 2 P.M. at Helder.

Having made several investigations relatively to these questions (which I have not been able to publish as yet in detail), I think it may not be without advantage to give at present conclusions relating to the results above noticed.

It is obvious that it is of the highest importance with relation to the research as to the cause or causes of the remarkable semi-diurnal oscillations of the barometer, that we should have only real variations of atmospheric pressure to deal with, and not instrumental irregularities; and that, if there is any part of the mean diurnal variations which is due to local causes, we should be able to separate that part from any other which may be due to general or cosmic causes.

When it is remembered that the range of the mean diurnal variation with us is from two to three hundredths of an inch of mercury, and that the epochs of maximum or minimum may be shifted an hour by a difference of one or two thousandths of an inch, it will be seen how essential it is that the instruments, the observations; and the corrections shall be the best, in order to be sure that we have real variations of atmospheric pressure before us.

In order to obtain the best possible results, my investigations have been limited to observations made in firstclass observatories with standard instruments. From observations made during several years at Makerstoun, Dublin, Greenwich, and Brussels, I have sought by the harmonic analysis the functions of sines which represent them most accurately. I give here the equations for the means of the three months in question-May, June, and July. The variation, $v$, is in ten-thousandths of an inch of mexcury; the origin for each of the four stations $\mathrm{M}, \mathrm{D}$, $\mathrm{G}$, and $\mathrm{B}$, is mean midnight $(\theta=0)$ :-

$$
\begin{aligned}
& \mathrm{M}, v=5^{6} \sin \left(\theta+355^{\circ}\right)+68 \sin \left(2^{\theta}+143^{\circ}\right)+2 \mathrm{sin}\left(3 \theta+171^{\circ}\right) \\
& \mathrm{D}, v=5^{1} \sin \left(\theta+35^{\circ}\right)+72 \sin \left(2^{\theta}+144^{\circ}\right)+25 \sin \left(3^{\theta}+153^{\circ}\right) \\
& \mathrm{G}, y=63 \sin \left(\theta+34^{\circ}\right)+88 \sin \left(2^{\theta}+143^{\circ}\right)+25 \sin \left(3 \theta+154^{\circ}\right) \\
& \text { B, } v=43 \sin \left(\theta+354^{\circ}\right)+9^{2} \sin \left(2 \theta+14^{\circ}\right)+24 \sin \left(3 \theta+10^{\circ}\right)
\end{aligned}
$$

The terms on the right of each equation represent the oscillations, whose superposition completes the whole diurnal variation. We find-

From the Ist term that the epochs of the maximum and minimum were the same within a few minutes at $M, D$, and $B$ (as shown by the arguments $355^{\circ}, 35^{\circ}$, and $\left.354^{\circ}\right)$, differing at Greenwich from the others by about $40 \mathrm{~m}$.

From the 2nd term, that of the semi-diurnal oscillation, that the epochs were the same at all the stations within a few minutes.

From the 3 rd term, that they agreed at $D$ and $G$ and at $M$ and $B$, those for the former being about $23 \mathrm{~m}$. different from those for the latter.

When we consider the coefficients of the different terms, which represent half the ranges of the oscillations, slight differences are found for the 1 st and 3 rd terms; for the and the range diminishes regularly as the latitude increases at the rate of 0 ooror inch for each degree of
latitude.

The exact agreement in the epochs of maxima and minima and the regularity of the variation of range with latitude in the semi-diurnal oscillation show that this oscillation obeys a general law. Dr. Lamont has supposed that the ist term, or single oscillation, is due to variation of temperature; this, I believe, is not the case. When we compare the terms for different seasons of the year, we find that for the same place the epochs of maximum and minimum may vary twelve hours in the single oscillation, while the epochs deduced from the same term for the temperature variations do not differ one hour. Not only so, I have found on the South Indian Ghats that the epochs deduced from the ist term of the barometric equations vary seven hours in ascending 6,000 feet $;$ while those shown by the and term are absolutely constant.

For all these reasons I conclude that the semi-diurnal oscillation of the atmospheric pressure is due to a cosmic cause, independent of local influences, while the single diurnal oscillation shows that part of the solar action which is modified by atmospheric conditions yet to be determined. The results for the four stations just given are a few links in a long chain of facts which tend to prove that the semi-diurnal oscillation of the barometer is due to an action of the sun, which is repeated equally, twice in each day, like the solar oceanic tide.

It will be seen, I think, from the results obtained from the Brussels, Greenwich, Dublin, and Makerstoun observations that the differences noticed at the beginning of this article cannot be allowed to enter as data into the domain of meteorology without much greater study of all the circumstances on which they depend. The facts of atmospheric variations are very difficult of explanation, but if we begin to admit results which may be purely instrumental among these facts explanation will become impossible.

It is a fact that the true temperature of the mercurial columns has not always been obtained, and when we have to discuss observations with self-registering instruments, many sources of error, including those of temperature on the apparatus itself, have to be cared for. ${ }^{1}$ At stations near the sea, such as Helder, Valentia, and Falmoutb, we have also to remember that in the varying height of the partial base of the atmosphere, througb the solir oceanic tide, there is a real cause of diurnal barometric osciliation whose amount and epochs should be ascertained and deducted before exact comparisons can be made with observations inland. At the same time I would remark that of the stations here considered Dublin is near the sea, while the others are more or less distant from it.

JOHN ALLAN BROUN

\section{MAROCCO AND THE ATLAS ${ }^{2}$}

$T \mathrm{HE}$ expedition of which an account is given in this most interesting volume was undertaken by $\mathrm{Sir}$ Joseph Hooker and Mr. Ball in the spring of $187 \mathrm{I}$, and lasted a little over two months. Many causes com-

${ }^{I}$ 'The observations here studied at the four observatories are all made by the eye.

2 "Journal of a Tour in Marocco and the Great Atlas." By Joseph Dalton Hooker, K.C.S.I., C.B., Pres. R.S., Directoriof the Royal Gardens, Kew; and John Ball, F.R.S., M.R.I.A. With an Appendix, including a ketch of the Geology of Marocco, by George Maw, F.L.S. (London: Macmillan and Co., 1878 .) 
bined to hinder the publication of this journal until now, from either the novelty or value of its contents.

The coast-line of the territory of Marocco extends from the frontier line of Algeria on the Mediterranean, along through the Straits of Gibraltar to the Atlantic Ocean, nearly opposite to the Canary Islands. Inland it would seem to have no absolutely well-defined boundary-line except towards Algeria, but it is supposed to stretch far into the Great Desert on the southern side of the Great Atlas range. Of this great region, possibly as large in extent as Spain, and the chief ports of which are within a few days' steaming of Southampton, almost nothing, if we except the 'mere coast-line, is known; and a journey across the dark continent itself seems easier of accomplishment than one to the town of Tarudant, in the southern valley of the Great Atlas.

The distance from Gibraltar to Tangiers is scarcely thirty-five miles. The five peaks of the Beni Hassan are seen from the Rock, yet we have no records of their having been investigated, and when the authors earnestly desired Sir John Drummond Hay, the British Minister Plenipo-

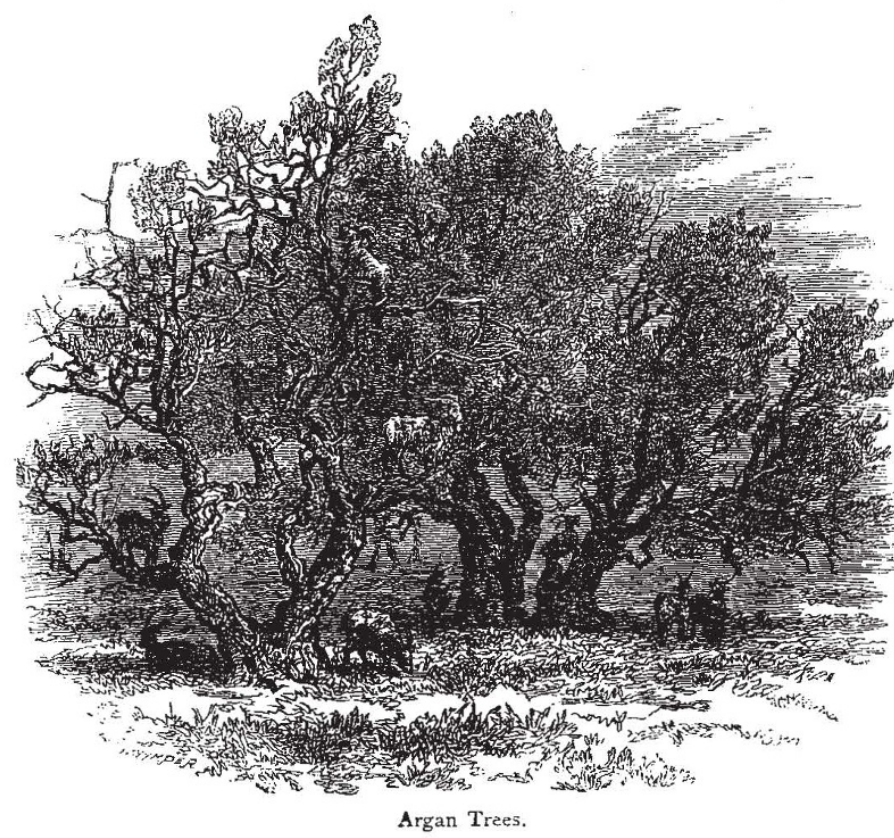
but the delay will, we feel sure, not in the least detract

that are gradually contracted to the thickness of whipcord, are beset with pellucid ruby-tipped glands, and present a peculiarity that appears to be unique in the vegetable kingdom. Any one who has remarked the growth of ferns must have seen that in the young state the leaves are rolled or curled inwards, so that in the process of unfolding the face or upper side of the leaf, which was at first concealed, is gradually opened and turned to the light. A similar process occurs in many other plants; but in Drosophyllum alone, so far as we know, the young leaf is rolled or curled the reverse way, so that the upper side of the leaf is that turned outwards. It appears to grow in many parts of Southern Portugal; reappears on the north side of the Straits of Gibraltar near Tarifa and Algeciras, and on the southern side about Cape Spartel and on the hills above Tetuan, where it commands a view of the opening of the Mediterranean, but extends no farther eastward."

Tetuan was visited from Tangiers. The season (April 10) was scarcely far enough advanced for the flowering of many of the sea-side plants, "but there was more than enough to rejoice the heart of a botanist, especially one escaping from the ghastly spring season of the north, where, when the days grow longer, they become only the more dreary, and where the bitter east winds parch and blast the young leaves and blossoms that are tempted to unfold themselves to their own destroying by the mildness of the winter weather." At Tetuan, Beni Hosmar was ascended. It was about $3, \infty 00$ feet high, and had not been ascended by any European since Barker Webb's time. The season was still too little advanced, and the botanist who will follow the travellers' footsteps about the beginning of June is promised a much richer harvest. Ceuta, about thirty miles from Tetuan, was next visited, and in order to catch the steamer to Mogador, our authors had to cross over to Gibraltar, from whence they again departed on April 20, in the Vérité, landing for a brief moment at Casa Blanca. They were in the port of Mogador on the 26 th.

Arrangements were soon made, through the goodness of the late Consul Carstensen, for the excursion to the Great Atlas. Mules were bought, the question of costume was decided, the interpreter of the Consulate, Abraham by name, was lent for the trip. The necessary escort consisted of four soldiers under the command of a captain. The necessary dinner at the Governor's was eaten, and about

tentiary in Marocco, to assist them in exploring their recesses, he was reluctantly obliged to pronounce against the feasibility of any such excursion, and even when they started for a short excursion to Cape Spartel it was considered prudent to give them an escort of two soldiers.

With this excursion the botanical interest of this journal begins. Plants of many sorts were seen and collected. Where a little slender stream ran through some damp meadows they were charmed by the delicate tint of a pale blue daisy that enamelled the green turf. It was merely a variety of the little annual daisy (Bellis annua) so common in many parts of Southern Europe ; but the blue tint does not seem to have been noticed elsewhere. The botanical district to which this northern corner of $\mathrm{Ma}$ rocco belongs has been called that of the cistus and heath. One very interesting plant to be often seen living in the Botanical Gardens of Kew and Dublin is thus described :-

"The most singular of these is the Drosophyllum Iusitanicum, a plant of the sun-dew tribe, whose branched stem bears several large yellow flowers. The numerous slender strap-shaped root-leaves, nearly a foot in length, 7 A.M. on the morning of April 29 the cavalcade took its departure from Mogador for Marocco. Instead of following the direct road, a detour nearly at right angles was made, to enable the botanists to gain a fuller acquaintance with the great Argan Forest. Their course was first from the coast, the tertiary calcareous rock that underlies the sand cropped out here and there, and the first Argan trees appeared.

"As we advanced, the trees grew larger and nearer together, and as we approached our intended halt, at a place called Douar Arifi, they formed a continuous forest.

"The Argan tree is in many respects the most remarkable plant of South Marocco; and it attracts the more attention as it is the only tree that commonly attains a large size, and forms a conspicuous feature of the landscape in the low country near the coast. In structure and properties it is nearly allied to the tropical genus Sideroxylon (Iron-wood); but there is enough of general resemblance, both in its mode of growth and its economic uses, to the familiar olive tree of the Mediterranean through a sandy soil, but as it rose and receded a little 
region to make it the local representative of that plant. Its bome is the sub-littoral zone of South-western Marocco, where it is common between the rivers Tensift and Sous. A few scattered trees only are said to be found north of the 'Tensift; but it seems to be not infrequent in the hilly district between the Sous and the river of Oued Noun, making the total length of its area about 200 miles. Extending from near the coast for a distance of thirty or forty miles inland, it is absolutely unknown elsewhere in the world. The trunk always divides at a height of eight or ten feet from the ground, and sends out numerous spreading, nearly horizontal branches. The growth is apparently very slow, and the trees that attain a girth of twelve to fifteen feet are probably of great antiquity. The minor branches and young shoots are beset with stiff thick spines, and the leaves are like those of the olive in shape, but of a fuller green, somewhat paler on the under side. Unlike the olive, the wood is of extreme hardness, and seemingly indestructible by insects, as we saw no example of a hollow trunk. The fruit, much like a large olive in appearance, but varying much in size and shape, is greedily devoured by goats, sheep, camels, and cows, but refused by horses and mules; its hard kernel furnishes the oil which replaces that of the olive in the cookery of South Marocco, and is so unpleasant to the unaccustomed palate of Europeans. The annexed cut, showing an average Argan, about twenty-five feet in height, and covering a space of sixty or seventy feet in diameter, with another, where goats are seen feeding on the fruit, exhibits a scene which at first much amused us, as we had not been accustomed to consider the goat as an arboreal quadruped. Owing to the spreading habit of the branches, which in the older trees approach very near to the ground, no young seedlings are seen where the trees are near together, and but little vegetation, excepting small annuals; but in open places, and on the outer skirts of the forest, there grows in abundance a peculiar species of Thyme $(T$. Broussonnetii), with broadly ovate leaves and bracts that are coloured red or purple, and the characteristic strong scent of that tribe. It is interesting to the botanist as an endemic species, occupying almost exactly the same geographical area as the Argan. As we afterwards found, it is replaced in the interior of the country by an allied, but quite distinct, species. Its penetrating odour seems to be noxious to moths, as the dried twigs and leaves are much used in Mogador, and found effectual for the preservation of woollen stuffs.".

Stopping at Shedma, Aïn Oumast, Sheshaoua, Misra ben Kara, Marocco was at last in view. From whatever side it be approached, this city presents an imposing appearance. The western side presented an outline about a mile and a half in length. Massive walls some thirty feet in height, with square towers at intervals of about I 70 yards, completely inclose it, and on two sides at least it is girdled by a wide belt of gardens in which the date palm, the olive, and fig; are conspicuous objects. We must refer the reader to the volume for an account of the sojourn in Marocco. Some difficulties with the Governor were got over by the quiet determination of Sir Joseph Hooker, whose knowledge of the Oriental character acquired in Asia here stood him in good service.

The outline of the Great Atlas range was quite visible from the terraced roof of the house in Marocco occupied by the travellers, though owing to the prevalence of clouds they failed to secure a satisfactory sketch of these. Through the kindness of Sir J. D. Hay, they are, however, enabled to insert a copy of a drawing made in I 829 by Mr. William Prinsep, the correctness of which they endorse. On May 8 Marocco was left for the mountains. The cavalcade was a large one, consisting of thirty-seven souls and thirty-three horses and mules. The baggage formed a good load for nine mules. The route lay south-east, but the upward slope became hardly perceptible, when before sunset they were compelled to stop for the night at the house of the Kaild of Mesfioua, at an elevation of about 2,400 feet over the sea. The next morning they were off pretty early, and soon began to ascend, often ricling along hollow ways between high banks or lofty hedges formed of tangled shrubs and climbing plants, in which were mingled some familiar forms with several altogether new.

"The date-palm had disappeared soon after we entered the hills; here, and elsewhere on our route, it seems to be confined to the lower region, rarely attaining the level of 3,000 feet above the sea. Its place was here supplied by the palmetto (Chamarops humilis), which seldom forms a trunk, perhaps because it is not allowed to attain a sufficient age. As we advanced, the vegetation constantly offered a more varied and attractive aspect; and one of our first prizes was a new species of thyme (Thymus maroccanus, Ball), somewhat like the species of the Argan zone, but with oblong leaves and uncoloured bracts. Of comparatively familiar forms there were Cistus monspeliensis and C. polymorphus, the first species of that genus that we bad seen in South Marocco, the pretty little Cleonia lusitanica, with many other Labiatæ. Of plants new to our eyes by far the most interesting was. the curious Polygala balansa. To those who know only the milkworts of Europe and North America it must seem strange to hear of a large shrubby Polygala, with branches that end in a sharp point, few small leaves, so quickly deciduous that it generally appears quite leafless, and large flowers of a showy purple-red colour. In truth, although there is great variety of form in this large genus, the species which is common throughout the lower valleys. of the Great Atlas is very distinct from all its congeners. In Arabia and South Africa there are some species forming dwarf bushes with spinescent branches, but in other respects very different. When full grown this is six or eight feet in height; and the round, green, almost leafless stems give it, when the flowers are absent, much the appearance of Spartium junceum, the large broom of Southern Europe.

"After riding some way up a rather steep stony track, we reached a grove of very fine olive trees, and our escort came to a halt. We had reached Tasseremout. For some time we had seen a large pile of solid masonry which crowned the hill immediately above the olive grove. This seemed to deserve a visit; but, on the other hand, the attractions of the surrounding vegetation were irresistible to botanists. The matter was settled by Hooker proceeding to visit the castle with the Kaïd, while Ball botanised, and Maw secured living specimens of some of the more interesting plants."

The castle of Tasseremout is one out of a large number of similar buildings standing on the northern outworks of the Great Atlas chain that will afford interesting matter for inquiry to future travellers when the country becomes more accessible, and the lessened jealousy of the natives will make a thorough examination of them less impossibje than it would be at present. The natives vaguely attribute their construction to Christians or Romans, the same word conveying either meaning; but the Jews often explain this to mean Portuguese. The general character of these buildings, as far as our information goes, is tolerably uniform. The walls are of great thickness and built of rough hewn stone: the arches are always rounded and the lower chambers vaulted; and they are evidently places of defence. There is little reason to believe that the Portuguese, who held at one time or other most of the Atlantic coast of Marocco, ever established a firm footing inland, and still less that they had such a hold on South Marocco as would be implied by the erection of a chain of forts along the f,oot of the Atlas. On the other hand, the history of Mauritania during the long period of the decline of Rome, and preceding the Saracen conquest, is an almost complete blank, save for a few apocryphal stories. 
It is certain that the lower country was once completely subject to Roman power and Roman institutions, and it remains to be ascertained how far an organised government survived the weakening of the central authority. That the independent tribes of the Atlas may have been inconvenient neighbours to the half-Romanised inhabitants of the plain is more than probable, and that the forts should have been erected to hold the former in check seems the most likely conjecture as to their origin. Excavation, whenever that may be practicable, will scarcely fail to tell something of the original occupants of these buildings, and to diminish our ignorance of a dark period of past history.

At sunrise on April to (a misprint for May Io) the thermometer stood at $60^{\circ}$, and the travellers were in the best of spirits for undertaking the work that seemed ready cut out for them. They would explore the fine valley that led directly from their camp station to the heart of the great mountain chain, up until they reached the snow; but here comes the exciting portion of the narrative, and the record of how their progress was checked, how they were forced to return, what troubles they had with their escort, how they camped in Ait Mesan Valley, and how

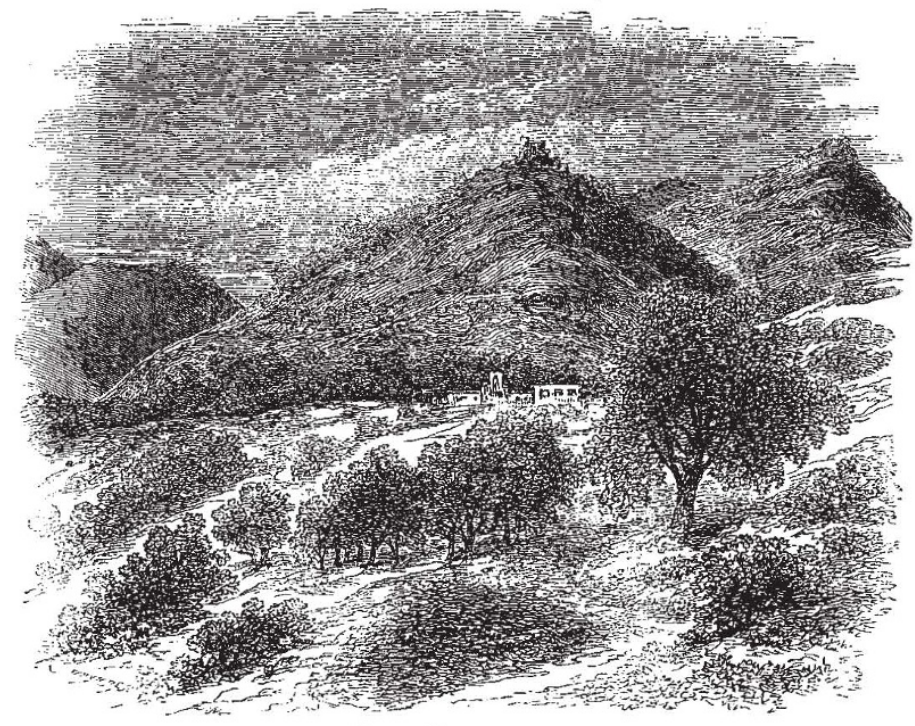

Furt at Tasserentout.

from thence they stole up into the snowy regions must be read in the journal; no abstracts would do the narrative justice. On the highest summit reached a snow-storm was encountered, and the cold was intense ; a thermometer carried in the pocket marked $25^{\circ} \mathrm{F}$., and the height of the Tagherot Pass was determined to be about I I,484 feet above the sea. The snow continuing, all further advance was impossible, and they descended again into the valley, to the Plateau of Sektana, from whence there was a glorious view of the Atlas, which was sketched by Mr. Ball. Amsmiz was reached about May I9; the position of the town reminded them of some of the villages in Piedmont that stand at the openings of some of the interior valleys of the Alps, or still more of similar places on the Apennines of Central and Southern Italy; and from it they reached the poor village of Imintelli, where they sojourned for two days. From Imintelli a desperate and fortunately successful attempt was made to climb to the summit of Djebel Tezah.

"Hooker reached the summit about 2 P.M., and was rejoined by Ball nearly half an hour later. Excepting some light fleecy cumuli floating over the low country to the north, at a lower level than the eye, the sky was cloud- less; but in some directions a thin haze obscured the details of the vast panorama. Our first glance was inevitably directed towards the unknown region to the south, and there, at a distance of fifty or sixty miles, rose the range of Anti-Atlas, showing a wavy outline, with rounded summits, and no apparent deep depression, rising, as we estimated, to a height of from 9,000 to 10,000 feet above the sea. The highest portion within our range of view, and the only part with a somewhat rugged outline, bore a few degrees west of due south, and corresponded in position with the Djebel Aoulouse of the French map. A somewhat darker shade traceable at some places on the flanks of this dimly seen range, possibly indicated the existence of forests, or at least of shrubs covering the slopes.

"When the first impulse of curiosity was partially satisfied, we began to take more careful note of our position, and to study in detail a view which had been so long denied to us. The first fact that struck us, was that the peak on which we stood lies a considerable way north of the watershed. The axis of the main chain, which here subsides into undulating masses from 2,000 to 3,000 feet lower than Djebel Tezah, lay between us and the central portion of the Sous valley, and, even if the prevailing haze over the lower districts had not veiled the details, would probably have cut off the course of the stream and the rich tracts that are said to fringe its banks. The higher strata of the atmosphere, above the level of about 7,000 feet, were, however, delightfully clear towards the east and west, and every feature of whatever portion of the main chain lay within our range was easily traced even at distances of thirty or forty miles. An extraordinary change had occurred during the three days since we had viewed the chain from Sektana, covered in deep snow down to the level of about 7,000 feet, and showing only a few crests of precipitous rock here and there protruding. The white mantle had now completely disappeared, and only long streaks of snow filling the depressions of the surface now seamed the flanks of the higher mountains, leaving the summit ridges everywhere bare. During the ascent of the northern face of the mountain, we had kept close to one of these long and comparatively narrow snow-slopes that extended through a vertical zone of over 2,000 feet, with a breadth of some 300 to 400 feet, and we now saw a still longer and wider strip of the same character, filling a shallow trough below us, on the east face of the peak. Near to the summit, and on the ridges leading to it, not a trace of snow was to be seen, even in the crevices of the rocks, where it would find partial shelter from the sun.

"We now proceeded to survey the field of view, in order, if possible, to fix the positions of any conspicuous summits. Looking due west, nothing approaching our level lay between us and the dim horizon. A succession of projecting spurs of the Atlas, dividing as many successive valleys, subsided into the plain; the most prominent, and that extending farthest from the main chain, being the mountain above Seksaoua. Turning the eye a little to the left, about west by south, we saw crowded together many of the higher summits of the western portion of the main range, which was here seen foreshortened, so that it was impossible to judge of their true relative position. The highest of these, seamed with snow, we judged to be about twenty-five miles distant, and higher than Djebel Tezah by 600 or 800 feet. In nearly the same direction, but only about ten miles distant, was a rugged projecting peak, rising some 300 feet above our level, and very many more of somewhat lower elevation were discernible in the space between us and the more distant points. Between 
S.W., and S.S.E., the range of Anti-Atlas, rising behind the broad Sous valley, bounded the horizon.

"At our feet, and cutting off from view the course of the river Sous, the mountain mass that here forms the axis of the main chain presented the appearance of a troubled sea of a light ferruginous colour, declining gradually in elevation from $W$. to $E$. At a distance of about eight miles E.S.E. of Djebel Tezah it sinks to an estimated height of little over 7,000 feet, at the head of the main branch of the Oued Nfys, and offers the only apparently easy pass over the main chain which we had yet seen. The rocky sunburnt flanks of the mountains were dotted with trees of dark foliage, doubtless some form of the evergreen oak, up to a height of about 8,000 feet above the sea, for the most part solitary, sometimes in clumps, but nowhere forming a continuous forest. The numerous feeders of the Oued Nfys had cut deep ravines in the flanks of the mountains, and were lost to sight, except twhere gleams of silver light shot upwards from the deeper valleys amid the walnut trees that fringed their banks. Numerous hamlets were seen, some perched upon projecting ridges, some lying in hollows and girdled with a belt of emerald-green crops.

"It was impossible not to speculate on the condition of these primitive mountaineers, who have since the dawn of history preserved their independence. Leo Africanus, speaking of the very district now overlooked by us, which he calls Guzula, says that the people were in his day molested by the predatory Arabs and by 'the lord of Marocco;' but they successfully resisted all encroachments, and no attempt is now made to assert the Sultan's authority among them, or to enforce tribute. Something they have doubtless gained in material, and still more in moral, welfare by stubborn resistance to alien rule; but the prosperity that is sometimes attained by tribes subject to the semi-feudal rule of chiefs, and among whom intestine feuds are rooted in immemorial tradition, is usually shortlived.

"Our hope of getting further knowledge as to the eastern extremity of the Sous valley, and the orographic relations between the Atlas and Anti-Atlas ranges was not to be satisfied. Djebel Tezah, as we found, stands some way north of the axis of the chain, while the great mass that rose over against us between E.N.E. and E.S.E., extending to the head of the Aït Mesan valley, sends out massive buttresses to the south, and by these our view of Anti-Atlas was cut off to the S.E. On one of these western projecting buttresses we could distinguish a large village belonging to the district of Tifinout, and standing at an elevation of nearly 7,000 feet. Turning our eyes to the north of true east, many of the higher summits of the chain were seen rising above the intervening ranges, the most distant probably belonging to the Glaoui group, east of Tasseremout. Once more we came to the conclusion that throughout the portion of the Great Atlas chain visible from the city of Marocco, between the easternmost feeders of the Oued Tensift and those of the Oued Nfys, there are no prominent peaks notably surpassing the average level. Many of them must surpass the limit of 13,000 feet above the sea, but it is not likely that any one attains the level of 13,500 feet. The last object that attracted our attention in the panorama, in a direction about east by north, was an isolated mass, forming a bold promontory on the northern side of the chain, of which a rough outline is here given.

"When the engrossing inlerest of the distant view bad so far subsided as to let us pay attention to nearer objects, we were struck by the unexpected appearance of considerable remains of dwellings on a platform of level ground, only a few feet below the actual summit of the mountain. About a dozen rude stone dwellings, all in a ruinous con-

$x$ This is apparently the pass spoken of by Leo Africanus as leading from meat Imizmizi (Amsmiz?) to the region of Guzula (the northern branch of the Sous valley). He says it is called Burris, that word meaning downy, because snow frequently falls there.-See "Ramusio," vol. i. p. 17, B. dition, with chambers sunk a couple of feet below the level of the ground, and the roofs fallen in, had at some former period been here erected ; but we saw no traces of recent occupation. It seemed most probable that they were intended as shelter for herdsmen, who had driven their flocks in summer to this lofty station.

"As we lingered on the topmost point of the mountain, the intense silence of the scene was broken by the distant scream of a large grey eagle that soared over our heads, and then sailed away southward over the Sous valley, making the deep stillness still more sensible than before."

No wonder that after the excitement of such a day, which only ended when their quarters were reached at half-past eight at night, the travellers let their collections rest in the collecting boxes and portfolios for the night, and after supper fell themselves to sleep.

Wars among the native tribes at last drove our authors to the necessity of returning to Mogador, passing through the wonderfully singular defile of Ain Tarsil, which is like a trench some thirty to fifty feet wide and the same deep, running for a length of nearly three miles. Four. days were spent on the occasion of the second visit to Mogador, and Sir Joseph Hooker reached London with his collections in safety on June $2 \mathrm{I}$.

Having in this notice exceeded the space at our disposal, we can only quite incidentally allude to the very valuable appendices to this volume, which treat of the geography, geology, and flora of the districts visited.

Since we some years ago closed the pages of "Palgrave's Personal Narrative of a Year's Journey through Central and Eastern Arabia," we have not perused a more delightful or instructive book of travels than this account of a tour in Marocco. From the well-known acquirements and great experience of the authors we expected much, and we have not been disappointed. The journal is, without doubt, especially pleasant reading to a botanist, but the geographer will find in it much to interest him, the politician will find in the description of the state of things now existing in such a country material for some serious thought, while the literary taste of every reader will be gratified by the excellent manner in which the narrative is written.

\section{REORGANISATION OF THE AMERICAN SURVEYS}

A LL well-wishers of the progress of geographical and geological research will welcome the intelligence that in the official estimates for the present year just presented to Congress the complete remodelling of the surveys carried on by the United States has been recommended to be immediately undertaken. The Report recently made by the National Academy of Sciences, to which attention was lately called in these pages (NATURE, vol. xix. p. 213), seems to have been adopted simpliciter. The Engineer Department is henceforth to be charged with no surveys save such as may be required for military purposes. The surveys of mensuration are to be placed under one organisation, and a new Geological Survey of the United States is to be instituted. Of course the changes are at present only recommended for adoption by the Committee on Appropriations, and there may be a struggle over some of the proposals. We hear indeed that the Engineers are leaving no point in their defence unguarded and are preparing for what is called a "heavy fight." For their own sakes as well as for the cause of scientific progress we cannot wish them success.

They object to the constitution of the Academy's Committee on the ground that only one of the members of it knows anything practically of surveying. And this objection will no doubt be urged with force and persistence in the debates in Congress. But surely they can hardly expect to throw dust in the eyes of the legislature by such a flimsy argument. The Committee, as we formerly pointed 